Fixed Point Theory, 22(2021), No. 2, 587-602

DOI: $10.24193 /$ fpt-ro.2021.2.39

http://www.math.ubbcluj.ro/ nodeacj/sfptcj.html

\title{
AN EXTRAGRADIENT ALGORITHM FOR THE SPLIT EQUILIBRIUM PROBLEMS WITHOUT PRIOR KNOWLEDGE OF OPERATOR NORM
}

\author{
VAHID DADASHI* AND TRUONG MINH TUYEN** \\ *Department of Mathematics, Sari Branch, Islamic Azad University, Sari, Iran \\ E-mail: vahid.dadashi@iausari.ac.ir \\ ** Department of Mathematics and Informatics, Thai Nguyen University of Sciences, \\ Thai Nguyen, Vietnam \\ E-mail: tuyentm@tnus.edu.vn
}

\begin{abstract}
In this paper, using the hybrid projection method and an extragradient method of Hieu in [9], we present an extragradient algorithm for approximating a solution of the split equilibrium problem. The strong convergence theorem is proved in the framework of Hilbert spaces under some mild conditions. In particular, our algorithm does not depend on the norm of the transfer operator. Key Words and Phrases: Hilbert space, split equilibrium problem, pseudomonotonicity, extragradient method.
\end{abstract}

2010 Mathematics Subject Classification: 68W10, 65K10, 65K15, 47H09, 47H10.

Acknowledgement. The first author is supported by Sari Branch, Islamic Azad University. The second author is supported by Thai Nguyen University of Sciences. All the authors are very grateful to an anonymous referee for providing them with useful comments and helpful suggestions.

\section{REFERENCES}

[1] Y. Censor, A. Gibali, S. Reich, Algorithms for the split variational inequality problem, Numer. Algorithms, 59(2012), no. 2, 301-323.

[2] V. Dadashi, H. Khatibzadeh, On the weak and strong convergence of the proximal point algorithm in reflexive Banach spaces, Optimization, 66(2017), no. 9, 1487-1494.

[3] V. Dadashi, M. Postolache, Hybrid proximal point algorithm and applications to equilibrium problems and convex programming, Journal of Optimization Theory and Applications, 174(2017), 518-529.

[4] B.V. Dinh, L.D. Muu, A projection algorithm for solving pseudomonotone equilibrium problems and its application to a class of bilevel equilibria, Optimization, 64(2015), 559-575.

[5] F. Facchinei, J.S. Pang, Finite-Dimensional Variational Inequalities and Complementarity Problems, Springer, New York, 2003.

[6] K. Fan, A Minimax Inequality and Applications. In Inequalities III, Academic Press, New York, 1972.

[7] K. Fan, Some properties of convex sets related to fixed point theorems, Math. Ann., 266(1984), 519-537. 
[8] Z. He, The split equilibrium problem and its convergence algorithms, J. Ineq. Appl., 2012(2012), doi:10.1186/1029-242X-2012-16.

[9] D.V. Hieu, Parallel extragradient-proximal methods for split equilibrium problems, Mathematical Modelling and Analysis, 21(2016), no. 4, 478-501.

[10] D.S. Kim, B.V. Dinh, Parallel extragradient algorithms for multiple set split equilibrium problems in Hilbert spaces, Numer. Algorithms, 77(2018), 741-761.

[11] I.V. Konnov, Combined Relaxation Methods for Variational Inequalities, Springer-Verlag, Berlin, 2000.

[12] G.M. Korpelevich, An extragradient method for finding saddle points and other problems, Matecon, 12(1976), 747-756.

[13] A. Moudafi, Proximal point algorithm extended for equilibrium problems, J. Nat. Geom., 15(1999), 91-100.

[14] A. Moudafi, The split common fixed-point problem for demicontractive mappings, Inverse Problems, 26(2010), 1-6.

[15] A. Moudafi, Split monotone variational inclusions, J. Optim. Theory Appl., 150(2011), 275-283.

[16] L.D. Muu, Stability property of a class of variational inequalities, Optimization, 15(1984), 347353.

[17] N. Nadezhkina, W. Takahashi, Strong convergence theorem by a hybrid method for nonexpansive mappings and Lipschitz-continuous monotone mappings, SIAM J. Optimization, 16(2006), 1230-1241.

[18] T.D. Quoc, L.D. Muu, N.V. Hien, Extragradient algorithms extended to equilibrium problems, Optimization, 57(2008), 749-776.

[19] R.T. Rockafellar, Monotone operators and the proximal point algorithm, SIAM J. Control Optim., 14(1976), 877-898.

Received: June 26, 2019; Accepted: April 14, 2020. 
